\title{
Study on the Integrated Education Path for Red Revolution and Patriotism-Taking the Battle Site of Xiangjiang River as an Example
}

\author{
Yao Liyan ${ }^{1, a}$,Zheng Nuojia ${ }^{1, b}$, Shi Mengqi ${ }^{2,}$, ,Fang Jiajue ${ }^{3, d}$, \\ ${ }^{1}$ School of Culture and Communication of Guangxi Science \& Technology Normal University; Laibin, Guangxi, China \\ 546199 \\ ${ }^{2}$ Student Affairs Office of Guangxi Science \& Technology Normal University; Laibin, Guangxi, China 546199 \\ ${ }^{3}$ Teaching Quality Monitoring and Evaluation Office of Guangxi Science \& Technology Normal University; Laibin, \\ Guangxi, China 546199 \\ 15878434051@163.com \\ b1093868846@qq.com \\ c404284591@qq.com \\ d, Jiayu10000@163.com
}

\begin{abstract}
Education is an important cornerstone of national revitalization and social progress. Under the background of the new era, the construction of socialist modernization promotes the all-round development of people and the all-round progress of society, which has put forward new and higher requirements for education. The relevant national policies continue to be issued to accelerate the development of education. Hands-on Inquiry Based Learning has become a new trend, which is a kind of open mode under the background of new curriculum reform and practice education. The organic integration of Red Revolution education and patriotism research is a major feature of it. Traditional and single in-school classroom teaching has been unable to meet the needs of cultivating students' practical ability and inquiring thinking. What they pursue is to go out of the classroom and get close to nature and life, so as to achieve the state of integration of man, nature and history. Under the impetus of internal demand and external environment, Hands-on Inquiry Based Learning (HIBL) emerges at the historic moment. At present, the state vigorously promotes patriotism education of primary and middle school students, cultivating a new generation of Young Red Revolutionary culture spirit, The government cooperates with various tourism agencies to set up special research institutions and train specialized talents for research and study travel. The government actively develops and researches various HIBL courses and teaching methods, and promotes the combination of Red Revolution education and patriotism research.
\end{abstract}

Keywords: Red Revolutionary education; Educational resources; Patriotism; HIBL travel.

\section{红色革命教育与爱国主义研学融合路径研究 以湘江战役遗址为例 \\ 姚丽妍 ${ }^{1, a}$, 郑婼嘉 ${ }^{1, b}$, 石梦琪 ${ }^{2, \mathrm{c}}$, 方家珏 ${ }^{3, \mathrm{~d}, *}$}

\author{
${ }^{1}$ 广西科技师范学院文化与传播学院; 广西 来宾 546199 \\ 2 广西科技师范学院学生工作处; 广西 来宾 546199 \\ 3 广西科技师范学院教学质量监控与评估处; 广西 来宾 546199 \\ 15878434051@163.com \\ b1093868846@qq.com \\ c404284591@qq.com
}




\section{${ }^{d, *}$ Jiayu10000@163.com}

摘 要: 教育是民族振兴、社会进步的重要基石。在新时代背景下，社会主义现代化建设、促进人的全面发展 和社会全面进步对教育提出了新的更高的要求。国家相关政策持续出台, 加快推动教育事业的发展, 研学教育 已然成为当前一种新趋势, 是新课程改革背景下一种开放式、实践式教育, 将红色革命教育与爱国主义研学有 机融合是研学教育的一大特色。传统且单一的校内课堂教学已无法满足学生培养实践能力和探究思维的需求, 他们追求的是走出课堂、亲近自然、贴近生活, 达到人与历史、自然互相融合的状态。在内部需求和外部环境 的推动下, 研学教育应运而生。当前, 国家大力推进中小学生爱国主义教育、培育新一代青年的红色革命文化 精神, 政府与各类旅游机构合作设立专门的研究机构, 并培养研学旅行的专门人才、积极开发研究各类研学课 程及教学方式, 推动了红色革命教育与爱国主义研学相两融合。

关键词: 红色革命教育; 教育资源; 爱国主义; 研学旅行

\section{1.前言}

爱国主义是中华民族的光荣传统和崇高美德, 是 中国人民维护民族独立和民族尊严的强大精神动力, 也是未成年人思想道德建设的核心。当前党和国家为 实现中华民族伟大复兴的目标不断做出努力, 为加强 新一代青年学生爱国主义教育、弘扬中国精神和践行 新时代的爱国主义、引导其责任化担当等方面提供了 各类政策支持, “综合中国教育体系和教育受众出台 满足红色革命精神和爱国主义教育相结合的研学教 育政策” [2]。爱国主义、红色精神为主题研学教育以 红色研学基地游学为依托, 以培养和加强各阶段学生 的社会主义核心价值观为目标, 充分挖掘爱国主义革 命文化和红色精神, 凝聚中国精神。首先在研学资源 较丰富的省市进行发展规划, 选取试点建设发展, 为 全面推进红色革命教育与爱国主义教育相结合的研 学发展规划提供经验借鉴, 最终建设全国范围内一体 化程度较高的综合性研学教育基地。本研究选取湘江 战役遗址作为试点, 推进红色革命教育与爱国主义研 学有机融合, 打造综合性研学基地, 分析探讨红色革 命教育与爱国主义研学融合路径。以此更直观地了解 历史、铭记历史, 继承并发扬红色革命精神。

\section{2.红色革命教育的内涵与意义}

\section{1 红色革命教育的内涵}

当前, 中国共产党和国家要求各阶层学生积极学 习中共党史、新中国史、改革开放史和社会主义发展 史, 其中党的十八大报告对加强教师队伍建设、深化 教育改革创新等方面明确提出现阶段教育事业发展 的目标任务, 充分体现党中央对教育事业的高度重视 和优先发展教育的坚定决心, 为我国教育改革发展指 明方向并提出更高要求。 ${ }^{[3]}$ 由此, 充分挖掘爱国主义 革命文化与红色精神, 凝聚中国力量, 发展红色革命 教育意义重大。广西拥有丰富的“红色研学”课程资
源。悲壮、关键的湘江战役发生在广西境内（兴安、 全州、灌阳等地），湘江战役纪念馆已成为“全国中 小学爱国主义教育基地”和“全国百家爱国主义教育 示范基地”。

湘江战役是中央红军长征突围以来最壮烈、最关 键的一仗, 历时七天, 中央红军突破了国民党反动派 的第四道封锁线, 为长征和中国革命的最终胜利打开 了前进的通途。以湘江战役纪念馆为研学基地, 开发 融合红色革命教育与爱国主义为主题的综合性研学 课程。其利用现代科学先进技术将场景和实物陈列, 重现当时红军的悲壮历史，以此告诫人民社会历史发 展艰难及现今来之不易, 让学生缅怀红色历史, 激发 青少年的爱国之心和历史精神, 挖掘和传承这段革命 先烈奋斗的历史。在针对青少年学生进行爱国主义教 育时, 需要进一步加强思政课改革创新, 在吸收中国 历史和中华优秀传统文化中爱国主义精神的同时, 还 需根据时代要求加以创造性转化和创新性发展。[4]湘 江战役遗址教育基地要求我们以抗战细节和抗战事 迹为基础, 把握大的方向讲好红色历史故事, 进而树 立红军光辉形象, 培养学生革命精神。此外, 要做好 几个重要战场和渡口的保护工作, 如纪念碑的烈士英 名墙等, 要将现有红色资源组合起来, 建设好湘江战 役遗址, 并将此作为爱国主义和红色革命教育基地的 有效研学资源。

\section{2 红色革命教育的重要意义}

红色革命教育能够加强中华优秀传统文化和中 国精神的培育, 可以深化中国特色社会主义教育和中 国梦的宣传教育; 推动中华优秀传统文化和红色革命 教育传承体系的构建和创新, 为培育和践行社会主义 核心价值观、落实立德树人等根本任务打下重要基 础。开展红色革命教育与爱国主义研学活动的目的就 是引导中小学生学习和传承中华民族优秀传统文化 并培养其爱国主义情怀, 宣扬红色旋律和满足红色革 命精神传承, 引导学生了解和感悟中国发展历史、挖 
掘爱国主义革命文化和红色精神, 培养各阶段学生的 社会主义核心价值观，优化学生“四个意识”，激发学 生的爱国热情和奋斗精神。[5]

推动红色革命教育即面向全国、面向世界讲好中 国故事，作为一名兼具爱国主义情怀的中国人，有责 任有义务讲好中国历史故事, 向学生们讲解属于我国 的民族历史, 传承中国精神, 培养他们成为德智体美 全面发展的社会主义建设者和接班人，加快中华民族 伟大复兴的发展速度。

\section{3.国内外中小学研学旅行的基本情况}

新时代下教育方式多样化的需求促使各类教学 教育方式应运而生, 其中就包括满足中小学生求知需 求的研学旅行教育。国外的研学发展速度较快, 态势 较好, 而国内研学发展受观念和环境等影响较国外发 展的速度慢且良莠不齐, 行业内部发展差异极大, 行 业集中度极低, 格局分散。目前教育部已初步完成覆 盖全国的国家级基地（营地）布局。经专家评议和营 地实地核查及综合评定, 在全国范围内分两批进行遴 选, 命名了 621 个研学旅行实践教育基地和营地, 构 建起以营地为枢纽、基地为站点的全国旅行研学实践 教育体系, 并建立了全国中小学生研学实践教育网络 平台; 目前研学课程开发有研学基（营）地、研学服 务机构及研学学校三种类型。[6]研学旅行已由促进旅 游业发展的单一角度, 上升到全面提高中小学生综合 素质教育的国家战略高度。

\section{1 国内外中小学研学旅行的兴起}

由于当前社会快速发展, 新时代下民众的思想观 念和教育观念较未改革开放之前有了较大提升, 研学 旅行的兴起能让学生充分体验区别于校园生活的风 土人情, 从而进一步加强学生实践体验式教育, 开拓 学生视野, 提高学生人际交往能力以及紧急情况应急 能力等。此外, 研学旅行注重实践学习和观光旅游并 重, 在其参观过程中, 提倡学生带着问题和思考进行 参观考察, 关注学生成长。鉴于国外研学旅行发展态 势尚好, 且形成了较为完备的一系列研学机构和建设 团队, 因此国内研学旅行应运而起。2016 年教育部 等十一个部门发布了《关于推进中小学生研学旅行的 意见》, 其中指出要将研学旅行纳入中小学教育教学 计划, 加强研学旅行基地建设, 并对组织管理、安全 责任体系和经费筹措机制进行了详细阐述。[7]

\section{2 国内外中小学研学旅行现存主要问题}

国外研学旅行发展速度较快、态势较好, 而国内 研学旅行发展存在较多问题。一是研学旅行的知名度 较低, 传播渠道较窄; 二是由于研学旅行存在一定的 安全隐患, 多数学校出于安全考虑, 限制学生参加研 学旅行课程; 三是由于家长对教育收获期望度高, 而 部分学生“游而不学”, 导致家长在不想负担高额费用 的同时对研学旅行产生怀疑; 四是无序价格竞争导致
研学旅行课程质量参差不齐, 劣币驱逐良币。

以上各种问题是国内研学旅行发展度较低的关 键, 其中涉及的利益相关者类型多, 实质的收益低, 而安全问题和教育实质内容方面则是研学旅行存在 的最大问题, 由于不能确保出行的绝对安全、课程内 容的绝对精彩及学生和家长的满意程度, 导致出现了 国内研学旅行发展程度低, 行业内部良莠不齐和集中 度低等问题。这需要我们加速研学旅行行业生态系统 的构建, 精准识别行业发展痛点并弥补关键短板。 ${ }^{[8]}$

\section{3 国内中小学研学旅行与爱国主义教育相结 合的情况概述}

我国国内研学发展依据教育为本、安全第一的原 则, 进行分阶段各级别不同课程设计, 突出小学、初 中、高中三个阶段分别以乡土乡情、市情县情、区情 国情研学为主的知行合一的研学旅行体系。各地依托 自然和文化遗产资源、大型公共设施、知名院校、工 矿企业、科研机构,建设一批研学旅行基地, 逐步完 善发展体系, 结合国情使研学旅行市场规范、健康发 展, 从而进一步加强我国中小学生爱国主义情怀。

2013 年教育部首次提出“研学旅行”, 对此各研学 机构和组织等首先在研学资源较丰富的省市进行规 划发展实践, 以小范围的研学试点实践发展为全面开 展研学教育活动提供经验, 同时国内也出台了许多相 关政策来支持研学旅行的发展, 将研学旅行纳入到中 小学课程体系, 教育部门将其纳入中小学教育计划, 以此加强研学旅行基地的建设, 促进研学实践教育。

\section{4.红色革命教育与爱国主义研学融合的可行 性}

\section{1 上级文件政策与研学目的相统一}

研学旅行作为一类新时代下新兴的教育方式, 目 的是致力于将探究性学习与旅行相结合, 寓教于乐。 为强调我国优秀传统文化教育的重要性和紧迫性, 强 调优秀传统文化教育的指导思想和各类基本原则以 及主要内容, 《完善中华优秀传统文化教育指导纲要》 提出各教育机构分学段有序推进中华优秀传统文化 教育, 把中华优秀传统文化教育系统融入课程和教材 体系, 加强对学生的红色革命教育与爱国主义精神的 培养, 同时加强地方对中华优秀传统文化教育的组织 实施和条件保障。2014 年 4 月, 教育部发布《教育 部关于培育和践行社会主义核心价值观进一步加强 中小学德育工作的意见》, 提出要改进实践育人, 充 分发挥各类社会实践基地、青少年活动中心 (宫、家、 站）等校外活动场所的作用, 组织学生定期开展参观 体验、专题调查、研学旅行、红色旅游等活动。2016 年 1 月, 在《中共教育部党组关于教育系统深入开展 爱国主义教育的实施意见》中, 教育部提出把爱国主 义教育作为弘扬爱国主义精神的永恒主题, 贯穿国民 
教育全过程，坚持爱国主义与社会主义相统一，加强 中国特色社会主义和中国精神的教育宣传; 维护祖国 统一和民族团结, 培养学生社会责任感, 增强学生的 国家认同感和民族认同感, 以此传承我国红色历史文 化和中国精神。2019 年 9 月, 中共中央“不忘初心、 牢记使命”主题教育领导小组印发了《关于在“不忘初 心、牢记使命”主题教育中加强爱国主义教育、弘扬 爱国主义精神的通知》，指出应在“不忘初心、牢记 使命”的主题教育活动中，加强爱国主义教育和弘扬 爱国主义精神的培育, 把弘扬爱国主义精神与扩大对 外开放结合起来, 传播中国精神, 凝聚奋进新时代的 磅礴伟力, 促进人类和平与发展。研学旅行项目迎合 了红色革命教育和爱国主义教育的精神传承, 对培养 爱国主义精神具有很大的政策需求。通过开展研学活 动可加强对中小学生的中华优秀传统文化教育和爱 国主义教育, 有效培养其对红色革命与爱国主义精神 的传承。

\section{2 学校思想政治教育与研学教育作用相统一}

学校的学科教育多是传统单一的, 以理论教育为 主的传统思政教学, 使得学生的认知层面仅局限于书 本范围, 没有突破新课改下的校本范围, 学生对现实 生活中的知识运用还有所欠缺; 而传统且单一的研学 教育, 没有思想政治教育的理论基础, 将难以实施。 传统的教学忽略了学生个体学习差异性和实践的主 观能动性, 使学生处于被动接受状态, 缺乏学习兴趣 和主动求知探索意识, 不利于其树立思政教学实践的 满足感以及社会主义的共同理想和共产主义的崇高 信念。[9]但学校思想政治教育与研学教育相结合, 组 织与开展各类团建活动, 可以让学生走出教室, 走出 课堂, 进行实地研学实践研究。通过实地研学活动, 拉近了人与人、人与历史、人与自然之间的距离, 能 让其构建友好和谐的关系。置身于历史遗迹, 将自己 代入其中, 以此更深入地了解历史。在活动中学习理 论, 在活动中实践理论, 做到学以致用、知行合一, 符合学校书本教育与研学实地教育相结合的整体性 和实践性原则。

\section{3 红色革命教育资源开发与爱国主义研学课 程开发相统一}

国家和地方重视对历史资源和红色革命资源的 保护, 注重对中小学生红色爱国主义教育的培养。为 了学生们更好地进行红色历史教育, 铭记历史和传承 红色经典, 各地政府和相关企业合作建立了城市博物 馆、红色教育基地、战争遗址或博物馆等, 研究并设 置了相应的研学课程。学生参与实地研学, 能够更直 面了解历史事件, 时刻牢记红色文化, 弘扬革命精神。 只有经过家国情怀的熏陶, 才能真正理解传统文化, 将自身实际与祖国历史紧紧联系在一起, 基础知识充 足、技能过关等都是基础, 真正的考验是对家国情怀 和民族认同的认知程度。 ${ }^{[10]}$ 中国是有着五千年历史的
文明古国，在这片土地上见证了许多的冲击、战争、 成长与发展, 一山一水都留下了岁月的痕迹, 这历史 的痕迹是家国情怀与优秀传统文化的重要体现, 基于 此的红色研学旅行则迎合了革命教育和爱国主义教 育的精神传承。

\section{5. 红色革命教育与爱国主义研学融合实施路 径}

\section{1 教育资源与研学课程资源开发相结合}

政府全面贯彻落实习近平总书记提出的“传承红 色基因, 发扬革命精神”重要指示, 立足并突出各地 自然文化遗产及相关教育资源, 从而进行研学旅行基 地的建设和开发。在此前提上，鼓励学校教育资源与 地方研学教育基地等资源统一, 建立联系, 达成合作, 开发和建设成学校爱国主义教育培训点, 在丰富学生 校园生活的同时也潜移默化地对学生们进行红色革 命历史的教育。

湘江战役纪念馆是国家爱国主义教育基地, 为纪 念红军长征第四道封锁线而建馆。馆内陈设着许多战 争遗址文物、战争情景重现、人物画相等, 一张张历 史照片, 一件件真实器物, 无一不令人感受到革命先 烈为国家、理想献身，舍小我为大家的无畏精神。其 作为国家级爱国主义教育基地, 并非单纯利用博物馆 资源进行红色研学资源开发，而是通过各类资源如教 师资源、文物资源、空间资源等进行互动互建、合作 共享的过程。[11]桂林市十二中学、南宁滨江路小学和 广西师大等学校, 先后针对湘江战役纪念馆及遗址设 计研学课程, 开展为期数天的红色研学教育, 重走红 军路、寻找英雄足迹, 感受红军革命精神, 意在通过 教育资源与研学课程资源开发相结合, 以怀着充满敬 意的心对为祖国作出巨大牺牲的战士们表达最诚挚 的告慰。

\section{2 校内校外爱国主义教育相结合}

\section{2 .1 充分发挥课堂教学的作用}

普通全日制中小学和职业教育学校, 将爱国主义 教育内容融入各学科教材编写和教育教学中, 普通高 校则将爱国主义教育与毛概、思修、马原等课程有机 结合, 加大爱国主义教育内容的比重。如成都市大邑 县三岔小学以积极传承红色文化为目标, 结合校园实 际开发红色校本课程。根据大数据时代发展潮流, 结 合新时代课程改革, 创新爱国主义教育形式, 利用互 联网传播速度快、范围广的功能, 开展网络学习活动, 鼓励开发微课、微视频等在线课程, 开发出符合并体 现爱国主义教育传承要求的音乐、美术、书法、舞蹈 等作品, 加强研学旅行导师的跨界融合, 吸收导游相 关技能和教育教学知识的专业化人才, 发挥和利用好 这些多种形式的研学旅行资源。[12] 


\section{2 .2 组织开展研学旅行活动, 合理利用爱国主 义研学教育基地}

各类爱国主义研学教育基地是新时代青年铭记 和接收民族历史、激发民族精神的重要传承地。组织 中小学生参观历史纪念馆、博物馆、战争遗址、烈士 遗墓等, 能够更好地了解红色革命历史, 引发情感共 鸣，从而达到爱国主义教育目的。

\section{3 各方面力量整合}

所谓的研学旅行是为了满足学生求知需求, 由学 校或旅行社及研学导师等多方面结合并根据所在区 域特色、各阶段学生年龄特点和各学科教学内容的需 要开展的课程活动, 但由于学校缺乏对户外研学活动 的实战经验, 所以研学旅行社等机构给学校的研学旅 行提供安全保障和技术支撑, 以及丰富的经验和相关 专业知识, 这两者的有机整合产生了良好的互补性。 研学旅行通过课程方式的改革创新, 组织学生以集体 旅行、集中食宿的方式走出校园，以一种拓展视野、 丰富知识, 加深与自然和文化亲近感的方式开展教学 活动, 充分发挥学生的主体作用, 采取启发式、交流 式的教学, 针对性地增强学生思想性和亲和力, 在教 育灌输和潜移默化过程中, 引导学生树立国家意识、 加强国家认同感, 增强中国特色社会主义和中国精神 的宣传, 为爱国主义传统注入新内涵, 为新时代爱国 主义教育作导向。[13]研学旅行已然成为现今时代下一 种开放式教育, 它继承和发展了我国传统游学满足学 生求知需求的教育理念和人文精神, 成为新课程改革 下素质教育的新内容和新方式。

\section{6.结论}

新课程改革下的研学旅行已然成为教育的一种 新形势, 它将红色革命教育与爱国主义研学有机融 合。一个国家的建立离不开民族的历史, 研学旅行教 育能够让我们更加直观地了解历史、铭记历史, 继承 和发扬革命精神, 习近平同志指出要让人民真正认识 到历史经历和未来发展道路, 要求我们把握真理和规 律, 根据实践运用指导生活, 从而正确把握社会历史 的发展趋向。[14]当前党和国家为实现中华民族伟大复 兴的目标不断努力, 将中国教育体系和教育受众相结 合, 为此提出了满足红色革命精神和爱国主义教育相 结合的研学教育, 为加强学生爱国主义教育、弘扬中 国精神和践行新时代的爱国主义、引导学生责任化担 当等方面提供了各类政策支持, 从而使得我国红色革 命教育与爱国主义研学相结合的教育工作得以高效 开展。

\section{项目基金}

本文为 2020 年国家级大学生创新训练计
划项目《桂中中小学爱国主义研学旅行的研究 与实践》（项目编号 202011546009）的阶段性 研究成果之一。

\section{REFERENCES}

[1] Hu Kai, Cheng Chi. (2017) Analysis of the development of outdoor education in advanced economies.EB/OL.:

http://doc.wendoc.com/bd5fedbeb1986a57638e435 1d955870fbf110b4af.html.

[2] Bai Yunhua. (2019) Several Important Provisions on the Patriotic Education of Young People in the New Era_-Based on the Analysis of the "Outline for the Implementation of Patriotism Education in the New Era".J. The Party Building and Ideological Education in Schools., 19:42-46.

[3] Xinhua News Agency. (2019) Implementation Outline of Patriotism Education in the New Era.EB/OL:

http://www.gov.cn/zhengce/2019-11/12/content_54 51352.htm.

[4] Li Yaxing, Yao Gongwu. (2020) The internal logic of Xi Jinping's important expositions on running ideological and political theory courses.J. Leading Journal of Ideological \& Theoretical Education.,04: 33-38.

[5] Zhang Yu. (2020) The Enlightenment of Xi Jinping's Language Art on the Teaching of Ideological and Political Theory.J. Leading Journal of Ideological \& Theoretical Education.,06:98-101.

[6] Li Xianyue, Zhang Liping. (2020) The Principles and Goals of the Development of Study Travel Courses in Primary and Secondary Schools.J. Liaoning Education.,20:53-56.

[7] Ministry of Education. Reading thousands of books must also travel thousands of miles-the Ministry of Education and other 11 departments issued the "Opinions on Promoting Study Trips for Primary and Middle School Students.EB/OL.:http://www.moe.gov.cn/jyb_xwfb /gzdt_gzdt/s5987/201612/t20161219 292360.html ,2016-12-19.

[8] Liu Jun, Chen Chen. (2020) The construction of a sustainable ecosystem for the research, study and travel industry in the post-epidemic era.J. Tourism Tribune.,09:7-10.

[9] Zhang Mezan, Liu Ying, Zhao Yuhong, Zhou Yujuan, Wang Danwen. (2020) Relying on Red Cultural Resources to Eliminate the Dilemma of Ideological and Political Education in Colleges.J. 
New West.,Z2:111-113.

[10] Xu Zhengzhong, Gu Huayi. (2020) An Analysis of the Cultivation of College Students' Family and Country Feelings Based on Chinese Excellent Traditional Culture.J. Sinogram Culture.,18:45-46.

[11] Wang Degang. (2020) Make the museum an important base for research travel.N. China Tourism News.,03: 1 .

[12] Gong Dedong.(2019) A Preliminary Study on How to Combine Intramural Education with Research Trips in the "China Sky Eye" Scenic Spot.J.
Tourism Today.,11:101.

[13] Wang Yi, Wang Fan. (2020) Theoretical Innovation and Path Optimization of "Outline of Implementation of Patriotic Education in the New Era".J. Leading Journal of Ideological \& Theoretical Education.,07:57-63.

[14] Hu Peng, Deng Shuhua. (2018) The Philosophical Implication of Xi Jinping's Thoughts on Science and Technology.J. Mao Zedong Thought Study.,03:63-66. 